\title{
O financiamento da educação na produção acadêmica de programas de pós-graduação no Brasil (2000-2010)
}

\section{The financing of the education in the academic production of post-graduate programs in Brazil (2000-2010)}

Márcia Aparecida JACOMINI ${ }^{1}$

Rosana Evangelista da CRUZ²

Resumo

Abstract

$\mathrm{O}$ artigo trata das produções acadêmicas sobre financiamento da educação de Programas de Pós-Graduação em Educação. Foram analisadas 56 teses e dissertações, defendidas entre 2000 e 2010, visando constituir um panorama da produçáo e localizar as contribuiçóes teóricas que têm maior presença na constituição desse campo de pesquisa. $\mathrm{O}$ estudo foi documental, com base nos resumos dos trabalhos, coletados no Banco de Teses da Capes e nas referências bibliográficas das referidas produçôes. Os resultados indicam que há um grupo de pesquisadores de financiamento da educaçáo que se apresenta como principal referencial teórico nas teses e dissertaçôes sobre o tema.

Palavras-chave: Política educacional. Financiamento da Educação. Produções Acadêmicas.
The article deals with the academic productions on the financing of postgraduate education, Fifty six theses and dissertations were analyzed between 2000 and 2010, aiming at establishing a panorama of production and analyzing the bibliography on the financing of education adopted in the works, with the objective of locating the theoretical contributions that have greater presence in the constitution of this field of research. The study was documentary, based on the abstracts of theses and dissertations, collected in the Bank of Theses of Capes and bibliographical references of the productions. The results indicate that there is a group of researchers financing education that presents itself as the main theoretical reference in the theses and dissertations on the theme.

Keywords: Educational policy. Financing of Education. Academic Productions.

1 Doutora em Educação. Professora da Escola de Filosofia, Letras e Ciências Humanas da Universidade Federal de São Paulo. E-mail: jacominimarcia@gmail.com.

2 Doutora em Educação. Professora do Centro de Ciências da Educação da Universidade Federal do Piauí. E-mail: rosanacruz@ufpi.edu.br.

R. Educ. Públ.

\section{Cuiabá}

v. 28

ก. 69

p. $653-675$ set./dez. 2019 


\section{Introdução}

A construção do campo acadêmico política educacional no Brasil é recente e está em processo de consolidaçáo, conforme indicam estudos de Azevedo e Aguiar (2001a, 2001b), Santos e Azevedo (2009), bem como Stremel (2016).

Como parte de sua consolidação, é importante a realização de pesquisas que tomem como objeto de estudo a produção acadêmica, posto que podem indicar características, tendências e lacunas da produçáo e contribuir para avançar na construção do campo. Ou seja, conhecer a produção sobre e de políticas educacionais é fundamental para fazer avançar esse campo acadêmico. Por isso, os estudos de revisão bibliográfica (FRANÇA; MATTA; ALVES, 2012), estado da arte (FERREIRA, 2002), revisōes sistemáticas (VASGERAU; ROMANOWSKI, 2004; DAVIES, 2007), metapesquisa (MAINARDES; TELLO, 2016), resguardadas suas especificidades, são contribuiçóes importantes para a identificação do acúmulo e das fragilidades dos campos de conhecimento.

A investigação intitulada $A$ produção acadêmica em politicas educacionais no Brasil: características e tendências (2000-2010) 3 tem enfrentado a discussão mais ampla sobre as pesquisas nesse campo, com base na análise de 1.283 teses e dissertaçóes defendidas no período de 2000 a 2010 em $20^{4}$ programas de pós-graduação em educação, cuja nota na avaliação da Coordenaçáo de Aperfeiçoamento de Pessoal do Ensino Superior (Capes), no triênio concluído em 2010, foi igual ou superior a cinco.

O recorte para coleta da produção discente dos programas de pós-graduaçáo em educação deveu-se à impossibilidade de o grupo de pesquisadores trabalhar com o conjunto das teses e dissertaçóes produzido no período em tela em todos os programas de pós-graduação em educação no Brasil, pois a avaliação trienal de 2007-2009 abrangeu 95 programas de pós-graduação em educação (BRASIL, 2010). Diante dessa limitação, optou-se por analisar os trabalhos defendidos nos programas melhor avaliados pela Capes naquele triênio. Entende-se que as teses e dissertaçóes que compóem o escopo da pesquisa constituem uma amostra

3 Esta pesquisa foi financiada pelo Edital n. ${ }^{\circ}$ 07/2011, MCTI/CNPQ/MEC/CAPES, Ciências Humanas e Sociais e envolveu pesquisadoras das seguintes universidades: Universidade Estadual de Feira de Santana, Universidade Federal de São Paulo, Universidade Federal da Grande Dourado, Instituto Federal Baiano, Universidade Federal de Pelotas, Universidade Federal do Rio de Janeiro, posteriormente incorporada pela Universidade Federal do Piauí.

4 Embora 21 programas de pós-graduação em educação tenham atendido aos critérios da pesquisa, o Programa de Pós-Graduação em Educação da PUC-SP selecionado não teve produção sobre políticas educacionais no período estudado. 
importante da produção acadêmica em políticas educacionais no Brasil durante os anos 2000.

Os programas que compõem o escopo da pesquisa são: 13 na região Sudeste: Universidades Federais de Minas Gerais (UFMG), São Carlos (UFSCAR), Espírito Santo (UFES), Uberlândia (UFU), Rio de Janeiro (UFRJ) e Baixada Fluminense (UFF); Universidades Estaduais do Rio de Janeiro (UERJ) e de São Paulo (USP, Unicamp e UNESP Marília); Pontifícias Universidades Católicas do Rio de Janeiro e de São Paulo (PUC/RJ, PUC/SP) e Universidade Metodista de Piracicaba (UNIMEP,); cinco na Sul: Universidades Federais de Pelotas (UFPEL), Paraná (UFPR) e Rio Grande do Sul (UFRGS), Pontifícia Universidade Católica do Rio Grande do Sul (PUC/RS) e Universidade Vale dos Sinos (UNISINOS); um no Centro-Oeste: Universidade Federal de Goiás (UFG); e uma na região Nordeste: Universidade Federal do Rio Grande do Norte (UFRN).

As teses e dissertaçóes foram coletadas no Banco de Teses da Capes no ano de 2012, com base num conjunto de palavras-chave pré-estabelecido, que permitiu a classificação dos trabalhos em nove eixos: 1) Planejamento e gestão, 2) Avaliação, 3) Qualidade, 4) Estado e reformas educacionais, 5) Políticas de formação de professor e carreira docente, 6) Financiamento, 9) Políticas inclusivas, 8) Análise de programas e projetos, 7) Abordagens teórico-metodológicas, 9) Políticas inclusivas e 8) Análise de programas e projetos.

Após coleta, que envolveu informaçóes sobre autor, orientador, instituição, título do trabalho, palavras-chave, resumo, ano, linha de pesquisa, tipo de trabalho (Mestrado ou Doutorado) e link para localização dos dados, passou-se à leitura e análise dos resumos em relação aos seguintes aspectos: tema específico, local onde a pesquisa foi realizada, tipo de pesquisa, procedimentos de coleta de dados, objetivos, problema de pesquisa, referencial teórico, resultados e qualidade do resumo.

Dos 1.283 trabalhos, 56 foram classificados no eixo 6, Financiamento, foco deste artigo. Os resumos destas teses e dissertaçóes serão analisados neste texto nos aspectos referentes ao ano e local de produção, tipo de trabalho, orientadores e temas abordados. Além desses aspectos, serão analisadas as referências bibliográficas adotadas pelos autores, conforme levantamento realizado nos trabalhos completos. Com isso, pretende-se apresentar as características gerais da produção que trata do financiamento da educação, com o objetivo de contribuir para maior conhecimento do campo acadêmico políticas educacionais, na temática específica financiamento da educação, e conhecer as principais referências que contribuíram para a constituição desse campo de pesquisa nos anos 2000.

A presença do tema financiamento da educação tem crescido nas discussões sobre políticas públicas e nas produçóes acadêmicas dos Programas de Pós- 
Graduação em Educação no Brasil, visto o reconhecimento da sua importância para a efetivação do direito à educação (GOUVEIA; SOUZA; TAVARES, 2006), no sentido da oferta de recursos imprescindíveis para a garantia de uma educação de qualidade. Por isso, é importante a realização de estudos que informem e analisem as características dessa produção, com proposto no trabalho ora apresentado.

O presente artigo está dividido em quatro seções, além desta introdução: breve discussão sobre as políticas de financiamento de educação no Brasil, tendo como marco inicial a Constituição da República de 1988 (BRASIL, 1988); apresentação e análise das características gerais das pesquisas sobre financiamento da educação que compóem este trabalho; caracterização das contribuiçóes teóricas que tiveram maior presença nas pesquisas sobre financiamento da educação realizadas nos programas de pós-graduação nos anos de 2000; e considerações finais.

\section{O financiamento da educação no Brasil}

O financiamento da educação tem papel fundamental para as políticas educacionais, pois os recursos financeiros são indispensáveis para viabilizar o direito à educação. Esse direito social é previsto entre outros direitos elencados no artigo $6^{\circ}$ da Constituiçáo Federal, portanto, reconhecido como essencial para o exercício da cidadania, condiçáo imprescindível para a plena realização humana.

No entanto, mesmo sendo a educação um direito fundamental, tendo sua importância reconhecida na legislaçáo e nos discursos de governantes, empresários e sociedade, inclusive com ênfase no seu papel no processo de desenvolvimento econômico, social e cultural da naçáo, os recursos disponibilizados para o setor são insuficientes para a garantia de acesso e permanência na escola com padrão adequado de oferta educacional (EDNIR; BASSI, 2009; PINTO, 2014; ARAUJO, 2014).

O financiamento da educação está previsto na Constituição Federal de 1988, mediante vinculação de recursos das diferentes esferas governamentais, pois o artigo 212 determina que a "União aplicará, anualmente, nunca menos de dezoito, e os Estados, o Distrito Federal e os Municípios vinte e cinco por cento, no mínimo, da receita resultante de impostos, compreendida a proveniente de transferências, na manutenção e desenvolvimento do ensino.” (BRASIL, 1988). Além dessas fontes, o setor conta com os recursos da contribuição social salárioeducação, voltada ao financiamento da educação básica.

Mesmo com a vinculação, a insuficiência de recursos se expressa nas condiçôes de oferta de grande parte das escolas públicas brasileiras, cujos 
problemas perpassam por questôes de deficiências na estrutura física e pedagógica; inexistência ou insuficiência de equipamentos e materiais didáticos; número elevado de profissionais da educação com formação inicial inadequada; ausência de políticas consistentes de formaçáo continuada; salários baixos que obrigam o professor a se desdobrar em várias jornadas de trabalho; falta de atratividade da carreira docente, resultante da desvalorização social e salarial sofrida pelos profissionais e superlotação de salas, entre tantos outros problemas que impedem o cumprimento do dispositivo legal que orienta a garantia de um padrão mínimo de qualidade de ensino (ALVES; PINTO, 2011; GOUVEIA; SOUSA, 2014; PINTO, 2014; GATTI, 2014).

Os esforços para reverter o processo de precarização da oferta educacional pública se materizalizam em proposiçóes de ampliação do investimento em educação, pauta permanente em espaços como os Congressos organizados pelo Fórum Nacional em Defesa da Educação Pública ${ }^{5}$ e as Conferências de Educação ${ }^{6}$. No âmbito da comunidade acadêmica, autores como Ednir e Bassi (2009), Pinto (2014) e Araujo (2014) também têm indicado a necessidade de ampliação do investimento na área.

O atual Plano Nacional de Educação (BRASIL, 2014), após longo processo de tramitação, definiu a aplicação mínima de $10 \%$ do Produto Interno Bruto na educação, até o último ano do decênio. Não obstante esse avanço das forças progressistas que defendem a educação como um direito humano fundamental, foi impresso no PNE, com vistas a computar os percentuais previstos na meta 20, a inclusão das despesas realizadas em programas de expansão da educação profissional e superior, inclusive incentivos fiscais e financiamento da educação infantil e especial ofertada por escolas confessionais, filantrópicas e comunitárias, nos termos do Artigo $5^{\circ}$, parágrafo $4^{\circ}$ do PNE n. ${ }^{\circ} 13.005 / 14$. Essa realidade, acrescida das açôes governamentais desenvolvidas, reitera uma perspectiva minimalista e privatista da educação, encaminhando-a para a esfera do mercado.

5 O Fórum Nacional em Defesa da Educação Pública, criado em 1986, organizou cinco Congressos Nacionais de Educação (Coneds), nos anos de 1996, 1997, 1999, 2002 e 2005, incidindo diretamente no processo de elaboração da LDB n. ${ }^{\circ} 9.394 / 96$ e do Plano Nacional de Educação n. ${ }^{\circ}$ 10.172/2001 (BOLLMANN, 2010).

6 As Conferências Brasileiras de Educação (CBE) foram realizadas de 1980 a 1991, sempre pautando as políticas educacionais e de financiamento na constituinte e na LDB (BOLLMANN, 2010). O governo federal, por açôes do Fórum Nacional de Educação, realizou as duas Conferências Nacionais de Educação (Conae), em 2010 e 2014, cujo tema principal foi a constituição do Sistema Nacional de Educaçáo, em regime de colaboração, a ser viabilizado pelo Plano Nacional de Educaçáo. 
Nesse sentido, mesmo políticas educacionais e de financiamento da educação que trazem em seu bojo o discurso de garantia do direito são limitadas por uma concepçáo de Estado e sociedade que desfavorece as camadas que dependem da educação pública para ter acesso a esse direito. Exemplo flagrante dessa realidade foi a instituição da política de fundos de maior impacto na educação brasileira, o Fundo de Manutenção e Desenvolvimento do Ensino Fundamental e de Valorização do Magistério (Fundef), em $1996 .^{7}$

$\mathrm{O}$ Fundef, visando à manutenção e ao desenvolvimento do ensino fundamental, tinha o objetivo proclamado "de assegurar a universalização de seu atendimento e a remuneraçáo condigna do magistério", nos termos da Emenda Constitucional n. ${ }^{\circ}$ 14/1996. No entanto, esse Fundo foi criado em um contexto de grande influência dos organismos internacionais, especialmente do Banco Mundial, nas políticas públicas brasileiras, os quais orientavam a necessidade de focalização dos gastos públicos em políticas direcionadas aos segmentos mais vulneráveis da sociedade, concepção que confrontava diretamente com a perspectiva universalista da Constituição Federal de 1988 (SHIROMA, 2000; PERONI, 2003).

O Fundef, fundo contábil de âmbito estadual, que vigorou de 1996 a 2006, vinculou a maior parte dos recursos da educação de estados e municípios ao ensino fundamental ${ }^{8}$, mediante sistema de redistribuição baseado no número de matrículas e na instituição de um valor por aluno/ano, definido pelo governo federal. Aqueles estados que náo alcançassem o valor mínimo definido anualmente receberiam uma complementação da União. Desse modo, o governo federal justificava o Fundef como uma política relacionada ao esforço para a garantia de um padrão mínimo de qualidade e de equalização nas condiçôes de oferta educacional entre regióes, estados e municípios.

No entanto, o valor por aluno definido pelo próprio governo federal durante a vigência do Fundef não correspondia ao necessário para a garantia de uma equalização da oferta, tanto que a complementação da União foi irrisória durante todo o período de vigência do Fundef (CRUZ, 2009), justamente por não estar baseada num custo qualidade, mas nas receitas que o governo disponibilizava para o gasto por aluno. O próprio governo federal desconsiderou a metodologia

\footnotetext{
7 A origem das políticas de fundos pode ser pesquisada em Lima (2006).

8 A Emenda Constitucional n. ${ }^{\circ} 14 / 96$ subvinculou 60\% de todos os recursos da educação provenientes de impostos e transferências de estados, municípios e Distrito Federal ao ensino fundamental. No entanto, o Fundef foi composto por 15\% dos seguintes impostos e transferências constitucionais: FPM, FPE, ICMS, IPI-Exportação e recursos da desoneração das exportaçôes, instituídos pela Lei Kandir (n. ${ }^{\circ}$ 87/96).
} 
de cálculo do valor por aluno prevista em lei, que deveria ser "nunca inferior à razão entre a previsão da receita total para o Fundo e a matrícula total do ensino fundamental do ano anterior, acrescida do total estimado de novas matrículas", nos termos do artigo $6^{\circ}$, parágrafo $1^{\circ}$, da Lei n. ${ }^{\circ} 9.424 / 96$, que regulamentou o referido Fundo (BRASIL, 1996).

O impacto desse Fundo na organização da oferta educacional e as críticas decorrentes de seu formato levaram a um movimento de grande mobilização pela instituição de um novo fundo, o qual foi construído em processo de ampla participação da sociedade civil, especialmente mediante o movimento PNE Pra'Valer, coordenado pela Campanha Nacional pelo Direito à Educação, entidade que congrega mais de 200 movimentos e entidades que lutam pela defesa da educação pública no país. ${ }^{9} \mathrm{O}$ resultado foi a aprovação, em 2006 , da Emenda Constitucional n. ${ }^{\circ}$ 53, que instituiu o Fundo de Manutenção e Desenvolvimento da Educação Básica e de Valorização dos Profissionais da Educação (Fundeb), com vigência de 14 anos, 2007 a 2020.

Diferentemente do Fundef, no Fundeb há ampliação dos recursos, agora envolvendo $20 \%$ de todos os impostos estaduais (ICMS, ITCMD, IPVA) e das transferências constitucionais do governo federal (FPE, FPM, IPI-Exp, Recursos da Desoneração das Exportaçóes - Lei Kandir, ITR), excetuando somente os impostos próprios municipais (ISS, IPTU, ITBI) ${ }^{10}$. No que tange às matrículas, o Fundeb inclui todas as etapas e modalidades da educação básica, com exceção da educação a distância. A participação da União na complementação dos fundos estaduais foi definida pelo mínimo de $10 \%$ do total do Fundo e houve reorganização dos Conselhos de Controle e Acompanhamento Social, visando alcançar maior efetividade.

Não obstante tais avanços, permanecem problemas centrais, como a ausência de metodologia para o cálculo do valor/aluno ano definido nacionalmente. Ao instituir anualmente o valor por aluno, o governo federal desconsidera o efetivo custo por aluno das diferentes etapas e modalidades contempladas pelo Fundeb, distanciando-se do que se tem como perspectiva

9 Coletânea de artigos organizada por Lima e Didonet (2006) que resgata o processo de construçáo do Fundeb.

10 Imposto sobre Circulação de Mercadorias e Serviços (ICMS), Imposto sobre Transmissão Causa Mortis e Doação (ITCMD), Imposto sobre a propriedade de veículos automotores (IPVA), Fundo de Participação dos Estados (FPE), Fundo de Participação dos Municípios (FPM), Imposto sobre Produtos Industrializados-Exportação (IPI-Exp.), Imposto Territorial Rural (ITR), Imposto sobre Serviços (ISS), Imposto sobre a Propriedade Predial e Territorial Urbana (IPTU), Imposto sobre a transmissão de bens imóveis (ITBI). 
para o alcance de um Custo Aluno Qualidade (CAQ), ou seja, um valor que garanta a oferta com padrão de qualidade, nos termos definidos na Lei de Diretrizes e Bases da Educação (LDB).

Dessa forma, o Ministério da Educação desconsidera o avanço alcançado pelo estudo sobre o Custo Aluno Qualidade Inicial (CAQi), desenvolvido pela Campanha Nacional em Defesa da Educação (CARREIRA; PINTO, 2007) e assumido pelo Conselho Nacional de Educaçáo, pelo Parecer n. ${ }^{\circ} 8 / 2010$, como referência para a matriz de financiamento da educaçáo no Brasil, a despeito de sua incorporação no atual Plano Nacional de Educação (Lei n. ${ }^{\circ}$ $13.005 / 2014)$.

O Fundeb ainda trouxe uma novidade até então não experimentada na matriz de financiamento da educação pública, qual seja, a inclusão das escolas de educação especial e atendimento na educaçáo infantil conveniadas, ofertadas por instituiçôes filantrópicas, confessionais e comunitárias, no repasse automático dos recursos do Fundo, indicando um avanço das perspectivas privatistas no âmbito do financiamento da educação.

A inserção das políticas que têm padrão que favorece a perspectiva privatista da educação tem como um de seus elementos fortes as influências dos organismos internacionais, especialmente do Banco Mundial que, ao realizar acordos de cooperação com o Brasil, mediante empréstimos, influencia a política, especialmente pelas condicionalidades presentes nos referidos acordos, sempre relacionados à mudança do padrão de gestão (FONSECA, 1998; NOGUEIRA, 1999; MONLEVADE, SILVA, 2000).

Portanto, o financiamento da educação, voltado a todos os níveis, etapas e modalidades da oferta educacional no Brasil, independentemente da vinculação de recursos, é condicionado pelas políticas governamentais que buscam minimizar o compromisso estatal com a manutenção da educação pública, justamente num contexto em que se exige a ampliação do investimento no setor, condição para o desenvolvimento de políticas de efetivação do direito à educação.

\section{Características de pesquisas acadêmicas sobre financiamento da educação}

O processo de classificação do conjunto de trabalhos selecionados para a pesquisa resultou em 56 resumos de teses e dissertaçôes classificadas no eixo 6, Financiamento, os quais foram analisados com vistas a traçar um perfil da produção acadêmica sobre a temática no recorte delimitado pelo estudo. A 
participação do financiamento no conjunto dos 1.283 trabalhos representou somente $4,4 \%$ do total dos trabalhos. No entanto, a pesquisa revelou um crescimento no decorrer dos anos uma vez que se observa o aumento da produção nos últimos seis anos (41 trabalhos) em comparação aos cinco primeiros (15 trabalhos). Esse movimento também foi verificado por Santos (2013), que concluiu que as pesquisas sobre financiamento da educação estão em processo de crescimento. No entanto, isso ocorre de maneira relativamente lenta se comparada a outras temáticas do campo das políticas educacionais.

Contudo, pesquisa sobre o tema vem tendo maior participação na agenda das entidades da comunidade científica e nas organizaçóes sociais e sindicais vinculadas à educação. Entre os espaços institucionais nos quais o financiamento da educação tem recebido significativa atenção estão: a Associação Nacional de Pesquisa em Financiamento da Educação (Fineduca); a Campanha Nacional pelo Direito à Educação; o Grupo de Trabalho (GT) 5, da Associação Nacional de Pós-Graduação e Pesquisa em Educação (Anped); a Associação Nacional de Política e Administração da Educação (Anpae); e a Confederação Nacional dos Trabalhadores em Educação (CNTE).

As referidas organizaçóes reconhecem que o financiamento da educação é condição para a efetivação das políticas educacionais que viabilizem o direito à educação, demandando, além do incremento dos recursos, a transparência e o controle social. Assim, o conhecimento dos mecanismos implicados no financiamento da educação é fundamental para a atuação nos Conselhos de Acompanhamento e Controle Social do Fundeb e em outros colegiados dedicados às questóes educacionais. Dessa forma, as pesquisas sobre o tema podem contribuir para o incremento da atuação dos setores da sociedade civil na defesa da escola pública no interior dos colegiados da área.

No que se refere ao nível do curso aos quais estavam vinculados os estudos aqui analisados, os trabalhos de mestrado foram, a maioria, seguindo a tendência de maior número de dissertações nos programas de pós-graduação classificados com notas cinco, seis e sete pela Capes, em 2010. Das 56 produçóes em financiamento da educação, 36 (63\%) são dissertações e 22 (37\%) teses. Compreende-se que existe a necessidade de ampliar as produçóes no âmbito do doutorado, seja pela maior profundidade deste tipo de pesquisa, seja pelo poder multiplicador dos egressos, que podem contribuir para disseminar esta importante linha de pesquisa no âmbito da graduação e pós-graduação nas universidades brasileiras(CRUZ; JACOMINI, 2017).

A necessidade de ampliar as produçóes sobre financiamento da educação em diferentes instituiçóes se revela pelo fato de que as pesquisas sobre esse tema, de acordo com os dados do estudo, se concentraram em algumas 
universidades. As com maior produção foram a Universidade Federal do Rio Grande do Sul (10); as Universidades de São Paulo (9) e de Campinas (9); e a Universidade Federal de Goiás (5). A Universidade Federal do Rio de Janeiro e a Universidade Metodista de Piracicaba tiveram três produçóes cada. Tiveram dois estudos sobre financiamento da educaçáo defendidos a Pontifícia Universidade Católica do Rio de Janeiro; as Universidades Federais Fluminense, de Minas Gerais, do Paraná, e de São Carlos e a Universidade do Vale do Rio dos Sinos. Nos 11 anos analisados, cinco Instituiçóes de Educação Superior (IES) produziram apenas um trabalho sobre o tema: Universidades Federais do Espírito Santo, de Pelotas, do Rio Grande do Norte e de Uberlândia e a Universidade Estadual Paulista - campus Marília.

Em relação aos orientadores das pesquisas sobre financiamento e controle social, observou-se que no período estudado dois nomes se destacaram, o da professora Nalu Farenzena, da Universidade Federal do Rio Grande do Sul, e o do professor Rubens Barbosa de Camargo, da Universidade de São Paulo, com nove e cinco orientaçóes, respectivamente. O professor Nelson Cardoso do Amaral e o professor Alberto de Mello e Souza, das Universidades Federais de Goiás e do Rio de Janeiro, respectivamente, orientaram três trabalhos cada um. Conquanto, o maior destaque é para o fato de 22 orientadores terem orientado apenas um trabalho no período e oito terem orientado dois. Esses dados informam que a pesquisa sobre financiamento da educação está em processo de crescimento, com a consolidaçáo de programas com orientadores voltados a essa temática.

Para identificar e classificar as temáticas das pesquisas, foram considerados os objetivos e os resultados apresentados nos resumos, sendo necessário destacar que em 17 os resultados não foram informados. Os temas abordados foram: Fundef/Fundeb (13), Controle social dos recursos, orçamento participativo e participação na elaboração de políticas (10), Financiamento do ensino superior e profissional (06), Financiamento da Educação Básica (06), Relações entre receitas, gastos educacionais, custo e condiçóes de oferta e qualidade (05), Participação dos entes federados no financiamento da educação (05), Autonomia financeira da escola (04), Valorização dos profissionais da educaçáo (03), Estudos comparados sobre financiamento da educação (03) e Instituiçôes financeiras multilaterais (01), cujo detalhamento foi apresentado por Cruz e Jacomini (2017).

Os temas supracitados também foram predominantes na pesquisa sobre o estado da arte da produçáo acadêmica em financiamento da educaçáo realizada por Santos (2013), o que indica certa centralidade dessas temáticas nas pesquisas sobre financiamento da educação. 


\section{Principais autores e obras utilizadas nas teses e dissertações estudadas}

Com a finalidade de conhecer quais autores e trabalhos (artigos, livros, capítulos de livros) foram adotados como referenciais nas pesquisas de mestrado e doutorado sobre financiamento da educação, nos anos 2000, procedeu-se à análise das referências bibliográficas. Do total de 3.397 obras citadas nas referências das 56 teses e dissertações, 1.215 foram citados em apenas um trabalho, indicando grande diversidade no uso de autores nas pesquisas sobre a temática naquele período.

No entanto, um grupo de 77 autores foram citados em 10 ou mais trabalhos. Entende-se que esses são os autores que se apresentaram como principais referenciais teóricos dos trabalhos analisados. Para proceder à análise dessas informaçóes, estritamente para fins didáticos, considerarse-á que os autores podem ser classificados em quatro grandes grupos: 1) autores no campo da metodologia de pesquisa; 2) autores implicados com campo de conhecimento mais amplo; 3) autores que estudam e pesquisam educação como área do conhecimento; 4) autores que se dedicam ao estudo do financiamento da educação, foco deste trabalho.

No que tange ao primeiro grupo, do ponto de vista da metodologia de pesquisa, foram citadas nas referências bibliográficas de 13 trabalhos sobre financiamento da educação as autoras Menga Lüdke e Marli André, denotando que elas têm sido importantes para a construção do desenho das pesquisas na área.

A educação e a política educacional, como campos multidisciplinares, dialogam com várias áreas de conhecimento, condição para a compreensão dos fenômenos sociais em suas múltiplas dimensôes. Essa realidade se revela no diálogo estabelecido pelos autores das teses e dissertações no escopo deste artigo, compondo o segundo grupo de referenciais citados 10 vezes ou mais no conjunto dos 56 trabalhos sobre financiamento da educaçáo, como pode ser observado na Tabela a seguir. 
TABELA 1 - Autores e número de vezes que foram citados nas referências das teses e dissertações sobre financiamento da educação (2000-2010). Grupo 2 - campo de conhecimento mais amplo

\begin{tabular}{|c|c|}
\hline Autor & Quantidade de citações \\
\hline BOBBIO, Norberto. & 33 \\
\hline ARRETCHE, Marta T. S. & 30 \\
\hline BOURDIEU, Pierre & 26 \\
\hline FIORI, José Luís & 23 \\
\hline BRESSER PEREIRA, Luiz Carlos. & 21 \\
\hline GRAMSCI, Antonio & 21 \\
\hline MARX, Karl & 21 \\
\hline OLIVEIRA, Francisco de. & 20 \\
\hline DRAIBE, Sônia & 19 \\
\hline CHAUÍ, Marilena & 18 \\
\hline GOHN, Maria da Glória Marcondes & 18 \\
\hline FERNANDES, Florestan & 16 \\
\hline SANTOS, Boaventura de Sousa. & 16 \\
\hline SOUZA, Celina & 14 \\
\hline COUTINHO, Carlos Nelson. & 13 \\
\hline SADER, Emir & 13 \\
\hline CASTRO, Cláudio de Moura. & 12 \\
\hline CARNOY, Martin & 11 \\
\hline FURTADO, Celso & 11 \\
\hline AFONSO, José Roberto Rodrigues & 10 \\
\hline BARROS, Ricardo Paes de & 10 \\
\hline COSTA, Messias & 10 \\
\hline LOBO, Thereza & 10 \\
\hline
\end{tabular}

Fonte: Elaborado pelas autoras com base nas referências bibliográficas das 56 teses e dissertações sobre financiamento da educação, extraídas do banco de dados disponível em Silva et al. (2014). 
A Tabela 1 revela que um grupo de 23 autores das áreas de Políticas Públicas, Ciência Política, Sociologia, Filosofia e Economia Política compuseram o referencial teórico e, por vezes, uma perspectiva e um posicionamento epistemológico dos autores das teses e dissertaçóes do escopo deste artigo. Esses autores não discutem especificamente educação e financiamento da educação, mas a produção deles foi relevante para, no mínimo, 10 autores das teses e dissertaçóes construírem suas análises acerca da temática em estudo.

Destaca-se, entre aqueles citados em pelo menos um terço dos trabalhos, que Bobbio, Bourdieu, Gramsci e Marx compóem o grupo de referências relacionado à perspectiva e posicionamento epistemológico dos pesquisadores do campo, nos termos definidos por Tello (2013). Arretche, Fiori, Bresser Pereira, Oliveira, Draibe, Chaui e Gohn são teóricos no campo das políticas públicas, economia, administração, filosofia e sociologia que oferecem contribuiçôes importantes para a compreensão do financiamento da educação como política pública no Brasil.

No que tange aos autores que estudam e pesquisam educação como área do conhecimento, que oferecem condiçóes de refletir sobre as políticas de financiamento da educaçáo, considerando os fins educacionais, no âmbito do conjunto das políticas voltadas ao setor, as referências citadas em 10 ou mais trabalhos apresentam-se a seguir.

TABELA 2 - Autores e número de vezes que foram citados nas referências das teses e dissertações sobre financiamento da educação (2000-2010). Grupo 3 - Educação

\begin{tabular}{l|c}
\hline Autor & Quantidade de citações \\
\hline SAVIANI, Demerval & 45 \\
\hline CURY, Carlos Jamil & 44 \\
\hline FREIRE, Paulo & 43 \\
\hline FRIGOTTO, Gaudêncio & 43 \\
\hline PERONI, Vera Maria Vidal & 27 \\
\hline CUNHA, Luiz Antônio & 26 \\
\hline SGUISSARD, Valdemar & 25 \\
\hline GUIMARÃES, José Luiz & 21 \\
\hline KUENZER, Acácia Zeneida & 19 \\
\hline CASSASSUS, Juan & 19 \\
\hline GENTILI, Pablo & 18 \\
\hline FONSECA, Marília & 17 \\
\hline
\end{tabular}




\begin{tabular}{l|c}
\hline Autor & Quantidade de citações \\
\hline LUCE, Maria Beatriz Moreira & 17 \\
\hline AZEVEDO, Janete Maria Lins de & 16 \\
\hline PARO, Vitor Henrique & 16 \\
\hline DOURADO, Luiz Fernandes & 15 \\
\hline NEVES, Lúcia Maria Wanderley & 15 \\
\hline CORAGGIO, José Luís & 14 \\
\hline HADDAD, Sérgio & 14 \\
\hline JACOBI, Pedro & 14 \\
\hline KRAMER, Sonia & 14 \\
\hline OLIVEIRA, Dalila Andrade & 14 \\
\hline TEIXEIRA, Anísio & 14 \\
\hline CAMPOS, Maria Malta & 13 \\
\hline BRANDÃO, Carlos Rodrigues & 12 \\
\hline DEMO, Pedro & 12 \\
\hline GADOTTI, Moacir & 12 \\
\hline SILVA JÚNIOR, João dos R & 12 \\
\hline TOMMASI, Lívia de & 12 \\
\hline LEHER, Roberto & 12 \\
\hline
\end{tabular}

Fonte: Elaborado pelas autoras com base nas referências bibliográficas das 56 teses e dissertações sobre financiamento da educação, extraídas do banco de dados disponível em Silva et al. (2014).

A compreensão das políticas de financiamento da educação precisa ser feita considerando sua função de viabilizar bases para a efetivação da educação como direito humano, no âmbito das políticas educacionais. Por isso, do grupo composto por 30 autores, não parece casual que Saviani, Cury, Freire e Frigotto tenham sido citados em mais da metade dos trabalhos analisados. Acompanham como referências principais Peroni, Cunha, Sguissard, Guimarães, Kuenzer, Cassasus e Gentili, referenciados em mais de um terço das monografias, o que revela a preocupação dos autores em situar o financiamento como uma política educacional no conjunto de ações estatais voltadas ao setor.

Os autores que têm se dedicado à produção sobre financiamento, citados em pelo menos 10 teses e dissertaçóes, estão expressos na Tabela a seguir. 
TABELA 3 - Autores e número de vezes que foram citados nas referências das teses e dissertações sobre financiamento da educação (2000-2010) - grupo 4 - Financiamento da Educação

\begin{tabular}{|c|c|}
\hline Autor & Quantidade de citações \\
\hline DAVIES, Nicholas & 103 \\
\hline PINTO, José Marcelino de R & 81 \\
\hline MELCHIOR, José Carlos Araújo & 79 \\
\hline OLIVEIRA, Romualdo L. Portela de & 75 \\
\hline MONLEVADE, João Antônio C. de & 64 \\
\hline CASTRO, Jorge Abrahão de & 61 \\
\hline FARENZENA, Nalú & 50 \\
\hline ARELARO, Lisete Regina Gomes & 42 \\
\hline VELLOSO, Jacques & 28 \\
\hline AMARAL, Nelson Cardoso & 24 \\
\hline NEGRI, Barjas & 18 \\
\hline CALLEGARI, César & 17 \\
\hline SOUSA JUNIOR, Luiz & 17 \\
\hline COSTA, Vera Lúcia Cabral & 16 \\
\hline XAVIER, Antônio Carlos da R & 16 \\
\hline ROMÃO, José Eustáquio. & 14 \\
\hline SENA, Paulo & 13 \\
\hline DUARTE, Marisa Ribeiro Teixeira & 12 \\
\hline BREMAEKER, François E. J. de & 11 \\
\hline CAMARGO, Rubens Barbosa de & 11 \\
\hline GOUVEIA, Andréa Barbosa & 11 \\
\hline VERHINE, Robert E & 11 \\
\hline GOMES, Cândido Alberto da Costa & 10 \\
\hline
\end{tabular}

Fonte: Elaborado pelas autoras com base nas referências bibliográficas das 56 teses e dissertações sobre financiamento da educação, extraídas do banco de dados disponível em Silva et al. (2014). 
A Tabela 3, que apresenta os 23 autores que pesquisam financiamento da educação, explicita que seis foram referências centrais nos 56 trabalhos analisados. Davies teve a maior participação, citado 103 vezes nas teses e dissertaçóes analisadas, seguido por Pinto (81), Melchior (79), Oliveira (75), Monlevade (64) e Castro (61). Também foram referenciados em mais da metade dos trabalhos Farenzena (50), Arelaro (42) e Veloso (28), seguidos por Amaral (24) e Negri (18).

Os dados revelam que a produção analisada, já nos anos 2000, apresentou algumas referências consensuais que substanciam a análise sobre o financiamento da educação em diferentes aspectos e realidades, elemento importante para a consolidação desse tema no âmbito das pesquisas do campo política educacional.

Para além do nome dos autores que foram referências centrais para as pesquisas sobre financiamento nos anos 2000, com o objetivo de conhecer os trabalhos mais citados, procedeu-se ao levantamento dos títulos que estavam nas referências de 10 ou mais teses e dissertaçôes, conforme a Tabela 4.

\section{TABELA 4 - Trabalhos e número de citação nas teses e dissertações sobre Financiamento da Educação (2000-2010)}

\begin{tabular}{l|c}
\hline \multicolumn{1}{c|}{ Obra } & Número de citações \\
\hline $\begin{array}{l}\text { MELCHIOR, J. C. A. Mudanças no financiamento da Educação no Brasil. } \\
\text { Campinas: Autores Associados, } 1997 .\end{array}$ & 25 \\
\hline $\begin{array}{l}\text { DAVIES, N. O FUNDEF e o Orçamento da Educação: desvendando a caixa preta. } \\
\text { Campinas, SP: Autores Associados, 1999. }\end{array}$ & 23 \\
\hline $\begin{array}{l}\text { PINTO, J. M. de R. Os recursos para a Educação no Brasil no Contexto das } \\
\text { Finanças Públicas. Brasília-DF: Editora Plano, 2000. }\end{array}$ & 23 \\
\hline MONLEVADE, J. Educação pública no Brasil - contos \& descontos. Ceilândia, DF: & 22 \\
Idéa, 1997. & 18 \\
\hline MELCHIOR, J. C. O financiamento da educação no Brasil. São Paulo: EPU, 1987. & 15 \\
\hline PINTO, J. M. de R. Financiamento da Educação no Brasil: um balanço do & 15 \\
Governo FHC (1995 a 2002). Educação \& Sociedade, Campinas, SP, v. 23, n. \\
80, set. 2002.
\end{tabular}




\begin{tabular}{|c|c|}
\hline Obra & Número de citações \\
\hline $\begin{array}{l}\text { DAVIES, N. O Tribunal de Contas e a educação: quem controla o fiscalizador } \\
\text { dos gastos governamentais em educação? Revista Brasileira de Estudos } \\
\text { Pedagógicos, Brasília: Editora Plano, } 2001 .\end{array}$ & 13 \\
\hline $\begin{array}{l}\text { LUDKE, M.; ANDRÉ, M. Pesquisa em educação: abordagens qualitativas. São } \\
\text { Paulo: EPU, } 1986 .\end{array}$ & 13 \\
\hline NEGRI, B. Financiamento da Educação no Brasil. Brasília: MEC/INEP, 1997 & 12 \\
\hline $\begin{array}{l}\text { CASTRO, J.A. Financiamento da Educação no Brasil. Em Aberto, Brasília, n. } 74 \text {, } \\
\text { p. 11-32, } 2001 .\end{array}$ & 11 \\
\hline $\begin{array}{l}\text { LOBO, T. Descentralização: conceitos, princípios, prática governamental. } \\
\text { Cadernos de Pesquisa, n. 74, p. 5-10, ago. de } 1990 .\end{array}$ & 11 \\
\hline $\begin{array}{l}\text { SAVIANI, D. A nova lei da Educação: trajetória, limites e perspectivas. } \\
\text { Campinas, SP: Autores Associados, } 1997 .\end{array}$ & 11 \\
\hline $\begin{array}{l}\text { ARELARO, L.R.G. Financiamento e Qualidade da Educação Brasileira: algumas } \\
\text { reflexões sobre o documento "Balanço do Primeiro Ano do Fundef - Relatório } \\
\text { MEC". In: DOURADO, L. F. (Org.) Financiamento da Educação Básica. } \\
\text { Campinas, SP: Autores Associados; Goiânia, GO: Editora da UFG, } 1999 . \\
\text { (Coleção Polêmicas do Nosso Tempo). }\end{array}$ & 10 \\
\hline $\begin{array}{l}\text { CUNHA, L.A. Educação, Estado e Democracia no Brasil. São Paulo: Cortez; } \\
\text { Eduff; Flacso, } 2005 .\end{array}$ & 10 \\
\hline DAVIES, N. O Fundef e as verbas da educação. São Paulo: Xamã, 2001. & 10 \\
\hline $\begin{array}{l}\text { FARENZENA, N. A política de financiamento da Educação Básica: rumos da } \\
\text { legislação brasileira. Porto Alegre: Editora UFRGS, } 2006 \text {. }\end{array}$ & 10 \\
\hline
\end{tabular}

Fonte: Elaborado pelas autoras com base nas referências das 56 teses e dissertações sobre Financiamento da Educação indicadas no banco de dados disponível em Silva et al. (2014).

No universo de 3.397 trabalhos, 19 foram citados em 10 ou mais teses e dissertaçóes. Entre eles, somente cinco não tratam diretamente do financiamento da educação: Educação, Estado e Democracia no Brasil; Pesquisa em educação: abordagens qualitativas; Política educacional e o papel do Estado no Brasil dos anos 1990; A nova lei de educaçâo: trajetória, limites e perspectivas e Descentralização: conceitos, princípios, prática governamental, citados entre 10 e 14 teses e dissertaçôes, conforme explicitado na Tabela 4.

No que tange aos trabalhos específicos sobre financiamento da educação, os mais citados foram: Mudanças no financiamento da Educação no Brasil (MELCHIOR, 1997); O FUNDEF e o Orçamento da Educação: desvendando a caixa preta (DAVIES, 1999); Os recursos para a Educação no Brasil no Contexto das Finanças Públicas (PINTO, 2000); e Educação pública no Brasil-contos \& 
descontos (MONLEVADE, 1997), referências citadas entre 22 e 25 vezes. Entre os 14 trabalhos mais citados, três são de autoria de Nicholas Davies, autor mais presente no conjunto das teses e dissertaçóes. Nesse grupo de obras, Melchior, Pinto e Monlevade têm dois trabalhos. Essas informaçôes reiteram a importância desses quatro autores no esforço para consolidar o financiamento da educaçáo como área de pesquisa no campo da política educacional nos anos de 2000.

\section{Considerações finais}

A temática financiamento da educação passou a ser abordada em teses e dissertaçóes com mais frequência após a instituição do Fundef no Brasil, em 1996. Hoje, já existe o reconhecimento da importância desses estudos para a formação de educadores, pesquisadores e gestores educacionais, posto que estấo relacionados diretamente à questáo da oferta educacional que viabilize este direito de cidadania.

No entanto, o tema ainda se apresenta entre os de menor participação $(4,4 \%)$ nas teses e dissertaçóes sobre políticas educacionais no conjunto das 1.283 produçóes analisadas na pesquisa, havendo prevalência de dissertaçóes, denotando a necessidade de aumento das pesquisas, principalmente de doutorado, isso porque são estudos com maior profundidade, desenvolvidos, em geral, por pós-graduandos vinculados ao sistema de ensino superior, possibilitando efeito multiplicador no âmbito da graduação e pós-graduação nas universidades brasileiras. A produção acadêmica sobre financiamento da educação, na amostra selecionada, está concentrada em instituiçóes públicas, em geral localizadas nas regióes Sudeste e Sul do país, 62\% e 28\%, respectivamente. As Pontifícias Universidades Católicas (PUC) de São Paulo, Rio de Janeiro e Rio Grande do Sul e a Universidade Metodista de Piracicaba (Unimep) são as únicas instituiçóes privadas representadas. Destacam-se em número de produçóes a Universidade Federal do Rio Grande do Sul (11), a Universidade de São Paulo (nove), a Universidade de Campinas (nove) e a Universidade Federal de Goiás (cinco).

Ao considerar a relação de orientandos por orientadores verifica-se certa fragmentação, já que, no período de 11 anos (2000 a 2010), 65\% orientaram de um a dois pós-graduandos, demonstrando que o financiamento da educação, naquela década, ainda era um tema de pesquisa em processo de construção nos Programas de Pós-Graduação.

Em relação às referências, do total de 3.397 obras presentes na bibliografia das 56 teses e dissertaçóes, 1.215 foram citadas em apenas um trabalho, indicando grande diversidade no uso de autores nas pesquisas sobre a temática 
naquele período. No entanto, um grupo de 77 autores foram citados em $10 \mathrm{ou}$ mais trabalhos, sendo estas as referências consideradas mais significativas para a produção em financiamento da educação nos anos 2000.

No que se refere aos autores no campo da metodologia de pesquisa, destacou-se Lüdke e André. Como campo multidisciplinar, a produção em financiamento da educação dialogou com áreas como Políticas Públicas, Ciência Política, Sociologia, Filosofia e Economia Política, áreas de conhecimento fundamentais para a compreensão dos fenômenos sociais em suas múltiplas dimensóes, destacandose 23 autores citados 10 vezes ou mais no conjunto dos 56 trabalhos. Bobbio, Bourdieu, Gramsci e Marx foram autores mais citados relacionados à perspectiva e posicionamento epistemológico. Arretche, Fiori, Bresser Pereira, Oliveira, Draibe, Chaui e Gohn compuseram um grupo de autores que contribuíram para a compreensão do financiamento como política pública no Brasil.

No campo da educação, destacam-se 30 autores dedicados à pesquisa sobre educação ou sobre políticas educacionais, especialmente Saviani, Cury, Freire e Frigotto, citados em mais da metade dos trabalhos analisados. Especificamente sobre financiamento da educaçáo destacaram-se 23 autores, dos quais seis foram referências centrais, citados mais de uma vez no conjunto dos 56 trabalhos analisados: Davies, Pinto, Melchior, Oliveira, Monlevade e Castro, indicando que, nos anos 2000, algumas referências foram consensuais para a análise do financiamento da educação, demonstrando a existência de um esforço para consolidar o tema como área de pesquisa no campo política educacional.

\section{Referências}

ALVES, T.; PINTO, J. M. de R. Remuneração e características do trabalho docente no Brasil: um aporte. 2011. Cadernos de Pesquisa, São Paulo, v. 41, n. 143. maio/ago. p. 606-638. Disponível em: http://www.scielo.br/pdf/cp/ v41n143/a14v41n143.pdf. Acesso em: 13 ago. 2019.

ARAÚJO, R. L. S. Limites e possibilidades da reduçáo das desigualdades territoriais por meio do financiamento da educaçáo básica. 2014. $416 \mathrm{f}$. Tese (Doutorado em Educação) - Faculdade de Educação, Universidade de São Paulo, São Paulo, 2014.

AZEVEDO, J. M. L. de; AGUIAR, M. A. da S. Políticas de educação: concepçóes e programas. In: WITTMANN, L. C.; GRACINDO, R. V. (Coord.). O estado da arte em política e gestáo da educação no Brasil (1991-1997). Brasília, DF: Anpae; Campinas, SP: Autores Associados, 2001a. p. 71-88. 
AZEVEDO, J. M. L. de; AGUIAR, M. A. da S. A produção do conhecimento sobre política educacional no Brasil: um olhar a partir da Anped. Educaçáo \& Sociedade, Campinas, ano XII, n. 77, p. 49-70, dez. 2001b.

BOLMANN, M. G. N. Revendo o Plano Nacional de Educação: proposta da sociedade brasileira. Educaçáo \& Sociedade, Campinas, v. 31, n. 112, p. 657-676, jul.-set. 2010.

BRASIL. Constituição da República Federativa do Brasil de 1988. Disponível em: http://www.planalto.gov.br/ccivil_03/constituicao/ConstituicaoCompilado.htm. Acesso em: 10 fev .2019.

BRASIL. Emenda Constitucional n. ${ }^{\circ}$ 14, de 12 de setembro de 1996. Modifica os arts. 34, 208, 211 e 212 da Constituição Federal e dá nova redação ao art. 60 do Ato das Disposições Constitucionais Transitórias. Disponível em: http://www.planalto.gov.br/ ccivil_03/constituicao/Emendas/Emc/emc14.htm. Acesso em: 13 ago. 2019.BRASIL.

Emenda Constitucional n. ${ }^{\circ}$ 53, de 196 de dezembro de 2006. Disponível em: http://www.planalto.gov.br/ccivil_03/constituicao/Emendas/Emc/emc53.htm. Acesso em: 13 ago. 2019.

BRASIL. Emenda Constitucional n. ${ }^{5}$ 59, de 11 de novembro de 2009. Brasília, 12 nov. 2009. Disponível em: http://www.planalto.gov.br/ccivil_03/constituicao/emendas/ emclemc59.htm. Acesso em: 05 fev. 2019

BRASIL. Emenda Constitucional n. 95, de 15 de dezembro de 2006. Disponível em: http://www.planalto.gov.br/ccivil_03/constituicao/Emendas/Emc/ emc53.htm. Acesso em: 15 dez. 2018.

BRASIL. Lei n. ${ }^{\circ}$ 9.394, de 20 de dezembro de 1996. Disponível em: http://www. planalto.gov.br/ccivil_03/leis/L9394.htm. Acesso em: 15 mar. 2017.

BRASIL. Lei n. ${ }^{\circ}$ 9.424, de 24 de dezembro de 1996. Disponível em: http://www. planalto.gov.br/ccivil_03/leis/L9424.htm. Acesso em: 15 mar. 2017.

BRASIL. Lei n. ${ }^{\circ}$ 13.005, de 25 de junho de 2014. Aprova o Plano Nacional de Educação - PNE e dá outras providências. Disponível em: http://www2.camara. leg.br/legin/fed/lei/2014/lei-13005-25-junho-2014-778970-publicacaooriginal144468-pl.html. Acesso em: 13 ago. 2019.

BRASIL. Coordenação de Aperfeiçoamento de Pessoal de Nível Superior. Relatório de Avaliaçáo 2007-2009: trienal 2010. Área de avaliação educação. 2010. Disponível em: http://trienal.capes.gov.br/wp-content/uploads/2011/03/EDUCAÇÃO-RELAVAL.pdf. Acesso em: 08 mar. 2011. 
CARREIRA, D.; PINTO, J. M. de R. Custo Aluno-Qualidade Inicial: rumo à educação pública de qualidade no Brasil. São Paulo: Global; Campanha Nacional pelo Direito à Educação, 2007.

CONSELHO NACIONAL DE EDUCAÇÃO/CÂMARA DE EDUCAÇÃO BÁSICA. Parecer CNE/CEB n. ${ }^{\circ}$ 8/2010, aprovado em 05 de maio de 2010. Estabelece normas para a aplicação do inciso IX do artigo $4^{\circ}$ da Lei ${ }^{\circ}$ 9394/96 (LDB), que trata dos padróes mínimos de qualidade para a Educação Básica pública. Brasília: CNE/CEB, 2010.

CRUZ, R.E. Pacto federativo e financiamento da educaçáo: a função supletiva e redistributiva da União - o FNDE em destaque. 2009. 434f. Tese (Doutorado em Educação) - Faculdade de Educação da Universidade de São Paulo, São Paulo, 2009.

CRUZ, R.E.; JACOMINI, M.A. Produção acadêmica sobre financiamento da educação: 2000-2010. Revista Brasileira de Estudos Pedagógicos, Brasília, v. 98, n. 249, p. 347-370, maio/ago. 2017.

DAVIES, P. Revisôes sistemáticas e a Campbell Collaboration. In: THOMAS, G; PRING, R. Educaçáo baseada em evidências: a utilização dos achados científicos para a qualificação da prática pedagógica. Porto Alegre: Artmed, 2007. p. 31-44.

EDNIR, M.; BASSI, M. Bicho de sete cabeças: para entender o financiamento da educação brasileira. São Paulo: Ação Educativa, 2009.

FERREIRA, N. S. de A. As pesquisas denominadas "estado da arte". Educaçáo \& Sociedade, Campinas, n. 79, p. 257-272, ago. 2002.

FONSECA, M. Financiamento do Banco Mundial à educação brasileira: 20 anos de cooperação internacional. In: TOMMASI, L.; WARDE, M. J.; HADDAD, S. (Org.). O Banco Mundial e as políticas educacionais. 2. ed. Sáo Paulo: Cortez, 1998. p. 229-253.

FRANÇA, C. de L; MATTA, K. W. da; ALVES, E. D. Psicologia e educação a distância: uma revisão bibliográfica. Psicologia: Ciência \& Profissão, Brasília, DF, v. 32, n. 1, p. 4-15, 2012.

GATTI, B. A atratividade da carreira docente no Brasil. São Paulo: Fundação Victor Civita, 2014.

GOUVEIA, A. B.; SOUZA, A. R. S. Desafios atuais para o financiamento de uma educação de qualidade. In: PINTO, J. M.; SOUZA, S. A. (Org.). Para onde vai o dinheiro? Caminhos e descaminhos do financiamento da educaçáo. São Paulo: Xamã, 2014. p. 21-40. 
GOUVEIA, A.B.; SOUZA, A. R.; TAVARES, T. M. Conversas sobre o Financiamento da Educaçáo no Brasil. Paraná: EDUFPR, 2006.

LIMA, M. J. Origem dos fundos para a educação: breve histórico. In: LIMA, M, J. R.; DIDONET, V. (Org.). Fundeb: avanços na universalização da educação básica. Brasília: MEC/INEP, 2006. p. 21-30.

LIMA, M. J. R.; DIDONET, V. (Org.). Fundeb: avanços na universalização da educação básica. Brasília: MEC/INEP, 2006.

MAINARDES, J.; TELLO, C. A pesquisa no campo da política educacional: Explorando diferentes níveis de abordagem e abstração. Arquivos Analíticos de Políticas Educativas, 24 (75), 2016. Disponível em: https:/epaa.asu.edu/ojs/ article/view/2331/1801. Acesso 13 ago. 2019.

MELCHIOR, J. C. A. Mudanças no financiamento da educação no Brasil. Campinas, SP: Autores Associados, 1997.

MONLEVADE, J. Educaçáo Pública no Brasil: contos \& descontos. Ceilândia: Idea Editora, 1997.

MONLEVADE, J. A. C. de; SILVA, M. A. Quem manda na educaçáo no Brasil? Brasília: Idéa Editora, 2000.

NOGUEIRA, F. M.G. Ajuda externa para a educaçáo brasileira - da USAID ao Banco Mundial. Cascavel: Edunioste, 1999.

PERONI, V. Política Educacional e papel do Estado - no Brasil dos anos 1990. São Paulo: Xamá, 2003.

PINTO, J. M. R. Dinheiro traz felicidade? A relação entre insumos e qualidade na educação In: PINTO, J. M.; SOUZA, S.A. (Org.) Para onde vai o dinheiro? Caminhos e descaminhos do financiamento da educação. São Paulo: Xamã, 2014. p. 147-168.

PINTO, J. M. R. Os Recursos para Educaçáo no Brasil no contexto das finanças públicas. Brasília: Ed. Plano, 2000.

PINTO, J. M. R. A política recente de fundos para o financiamento da educação e seus efeitos no pacto federativo. Educaçáo \& Sociedade, Campinas, v. 28, n. 100, p. 877-897, out. 2007.

SANTOS, A. L. F. dos; AZEVEDO, J. M. L de. A pós-graduação no Brasil, a pesquisa em educação e os estudos sobre a política educacional: os contornos da constituição de um campo acadêmico. Revista Brasileira de Educaçáo, Rio de Janeiro, v. 14, n. 42, p. 534-605, set./dez. 2009. 
SANTOS, A. S. R. Financiamento da educaçáo no Brasil: o estado da arte e a constituição do campo (1996 a 2010). Jundiaí: Pacto Editorial, 2013.

SHIROMA, E. O. et al. Política Educacional. Rio de Janeiro: DP\&A, 2000.

SILVA, A. A. (Coord.) et al. Produção acadêmica em políticas educacionais no Brasil - 2000-2010: dados dos programas conceito 5 ou mais. [banco de dados]. Pesquisa financiada pelo CNPq, Edital/Chamada CNPq/CAPES no 07/2011. Feira de Santana: Cede, 2014. Disponível em: http://www2.uefs.br/cede/docs/aproducao-academica-em-politicas-educacinais-2000-2010.pdf. Acesso em: 12 fev. 2016.

STREMEL, S. A constituição do campo acadêmico da política educacional no Brasil. 2016. 316f. Tese (Doutorado em Educação) - Setor de Ciências Humanas, Letras e Artes da Universidade Estadual de Ponta Grossa, Ponta Grossa, 2016.

TELLO, C. Las epistemologias de la política educativa - notas históricas y epistemológicas sobre el campo. In: TELLO, C. (coord. y compilador). Epistemologías de la política educativa: posicionamentos, perspectivas y enfoques. Campinas, SP: Mercado das Letras, 2013, p. 23-68.

VOSGERAU, D. S. R.; ROMANOWSKI, J. P. Estudos de revisão: implicaçôes conceituais e metodológicas. Revista Diálogo Educacional, Curitiba, v. 14, n. 41, p. 165-189, jan./abr. 2014. 